\title{
ANONIMIZAÇÃO DO DOADOR E BIOBANCOS DE REPRODUÇÃO ASSISTIDA
}

\author{
Alexandra Clara Ferreira Faria ${ }^{1}$ \\ Roberto Henrique Pôrto Nogueira ${ }^{2}$
}

Resumo: O estudo objetiva analisar se há conflito entre direito ao conhecimento da ascendência biológica e direitos da personalidade (anonimização ou confidencialidade de dados) do doador do material biológico humano armazenado em biobancos, consoante o $\S 3^{\circ}$ do art. 17 do Provimento do Conselho Nacional de Justiça n. 63/2017. A relevância do problema é evidente porque o tema estudado carece de regulamentação legal e envolve o embate de interesses próprios de sujeitos vulneráveis. A pesquisa é jurídico-teórica, sobretudo bibliográfica. Como resultado, conclui-se que o conhecimento da ascendência biológica pela criança gerada por técnicas de reprodução humana assistida não viola os direitos da personalidade do doador.

Palavras-chave: Biobancos; Biotecnologia; Ascendência Biológica; Anonimização; Doação.

\section{ANONYMITY OF THE DONOR IN BIOBANKS OF ASSISTED REPRODUCTION}

\begin{abstract}
The objective of this study is to analyze whether there is a conflict between the right to knowledge of biological ancestry and the personality rights of the donor of human biological material stored in biobanks, according to $\S 3$ of art. 17 of n. 63/2017 provision of Brazilian 'Conselho Nacional de Justiça'. The relevance of the problem is evident because the subject lacks legal regulation and involves vulnerable individuals. The study is theoretical, mainly bibliographical. It is concluded that knowledge of biological ancestry by the child generated by assisted human reproduction techniques does not violate the donor's personality rights.
\end{abstract}

Keywords: Biobanks; Biotechnology; Biological Ancestry; Confidentiality; Donation.

\footnotetext{
${ }^{1}$ Doutora em Direito Privado pela PUCMinas. Mestre em Direito Constitucional pela UNAERP - Ribeirão Preto/SP Especialista em Direito Público da UNIFEMM. Professora Adjunto IV da Faculdade Mineira de Direito da PUCMinas. Professora da Pós Graduação do Instituto de Direito Continuado -IEC da PUCMinas. Advogada.

${ }^{2}$ Doutor e Mestre em Direito Privado pela PUCMinas. Especialista em Direito Tributário pela Faculdade de Direito Milton Campos. Professor Adjunto do Curso de Graduação e Mestrado Acadêmico em Direito da UFOP.
} 


\section{CONSIDERAÇÕES INICIAIS}

A Biotecnologia impulsiona o Direito a desenvolver novas teorias, com a finalidade de compreender os elementos inéditos oriundos da extrema complexidade social da atualidade, principalmente no âmbito da Genética.

As pesquisas clínicas e o próprio armazenamento de dados e materiais biológicos humanos para o estudo e desenvolvimento de novas tecnologias envolvendo a Genética devem respeitar direitos fundamentais constitucionais horizontalmente eficazes, tendo em vista a proteção dos direitos da personalidade pelo Estado Democrático de Direito. Assim, a manipulação de dados e materiais biológicos humanos devem sofrer alguma restrição e controle, de modo a assegurar, assim, a anonimização do doador, tida como confidencialidade de dados ligados a direitos de personalidade desse sujeito.

Entretanto, os procedimentos de pesquisas clinicas, técnicas de reprodução humana e os biobancos não são regulados por legislação federal de tratamento específico, mas somente por resoluções do Conselho Nacional de Saúde (CNS) e Conselho Federal de Medicina (CFM). Merece destaque, ainda, a Lei de Biossegurança e seus decretos regulamentadores, que, por sua vez, não contemplam, suficientemente, toda a problemática apresentada pela inovação tecnológica.

Logo, a divergência entre os parâmetros chancelados pelos órgãos reguladores e os empregados pelos pesquisadores e geneticistas podem derivar do desconhecimento das peculiaridades normativas, o que pode deixar o doador do material biológico humano e seus dados genéticos sem a devida proteção, acarretando, assim, o receio da revelação indesejada de sua identidade pessoal e social.

Neste contexto, cabe indagar se o doador do material biológico humano pode acabar sofrendo a violação de seu direito à anonimização ou de preservação de dados identitários (anonimização entendida como confidenciaçidade no que se refere à preservação de sua identidade na participação em processo de colaboração para iniciativa de constituição de biobanco), em virtude do Provimento n. 63 do Conselho Nacional de Justiça (2017), no momento do registro civil de nascimento, tudo em razão da obrigatoriedade da declaração firmada pelo responsável diretor técnico indicando a realização das práticas de reprodução humana assistida, na qual constaram os beneficiários; bem como do direito ao conhecimento da ascendência biológica. 
Entretanto, através da leitura do $\S 3^{\circ}$ do art. 17 do referimento provimento, emerge um conflito do direito a um eventual conhecimento da ascendência biológica da criança gerada a partir da utilização de técnicas de reprodução humana heteróloga e da preservação da identidade do doador, uma vez que alguma documentação deverá ser apresentada ao serviço notarial. Logo, delineia-se um questionamento: como assegurar a preservação da identidade do doador de material biológico humano quando da consulta da ascendência biológica da criança oriunda da articulação de seu material biológico, para ocultamento de dados identitários, nos moldes de sua decisão? Como, efetivamente, compreender a manifestação da autonomia privada do doador para eventual disposição e manipulação de seus dados genéticos e material biológico humano para biobancos?

Os avanços tecnológicos no âmbito da genética, nos mais diversos campos regulados pelo Direito, fazem com que sejam descortinadas possibilidades inúmeras de operações e violações ao sistema jurídico. Assim, compete ao Direito a atribuição de processar e integrar esses novos impasses à ordem normativa jurídica nacional.

Nesse contexto, será possível o conhecimento de todas as informações pertinentes ao titular do material biológico humano doado para os biobancos? Em quais circunstâncias isso é admissível? O doador do material biológico humano tem o direito à ocultação de seus dados identitários (o que aqui se chamou de anonimização)? Há possibilidade de separação da identidade pessoal e social da identidade biológica?

É exatamente esse o escopo principal do estudo, vale dizer, a busca pela conformação desses interesses aparentemente conflituosos, considerado o panorama dos direitos e garantias fundamentais. Significa que, argumentativamente, pode ser viável definir quais informações podem ser divulgadas a respeito da ascendência biológica e sua aplicação na seara do Biodireito, para constatar o possível reconhecimento de um novo direito, qual seja, o direito do doador de ocultação de sua pessoalidade, vale dizer, da identidade pessoal e social.

Para uma conclusão coerente acerca da controvérsia apresentada, é essencial analisar os direitos da personalidade e seu regime jurídico, as informações biogenéticas, os biobancos para técnicas de reprodução humana e a normatização pertinente.

Diante disso, a temática é de relevância social, haja vista que, a despeito dos biobancos existentes, há necessidade do estudo jurídico-sistemático da celeuma para a adaptação dos instrumentos existentes com essa nova realidade, de modo a preservar os atos de disposição do 
corpo como exercício de autonomia privada, consagrando, assim, o exercício dos direitos da personalidade.

O problema pode ser abordado por uma infinidade de vieses. A escolha é de enfrentar a viabilidade de resguardar a anonimização (confidencialidade de dados) do doador do material biológico humano, para a garantia de informações de cunho personalíssimo armazenadas em biobancos de dados genéticos e biológicos, sob a ótica da relação jurídica estabelecida pela doação neutra.

A hipótese a ser testada é de que cabe dissociar a ancestralidade biológica da identidade pessoal e social do doador de materiais biológicos armazenados em biobancos de reprodução humana assistida. Cabe, assim, a divulgação de informações para a finalidade de verificação de aspectos genéticos, ao mesmo tempo que se assegura a privacidade (usualmente descrita como intenção de anonimização por parte do doador) e, portanto, a proteção de direitos da personalidade.

Para tanto, a metodologia utilizada é a jurídico-teórica, com coleta de dados em material documental, obtidos por meio de pesquisa bibliográfica, visando a uma contribuição de conteúdo específico e técnico.

\section{DIREITOS DA PERSONALIDADE COMO EXPRESSÃO DO DIREITO AO CORPO HUMANO}

A concepção do corpo humano ao longo da história demonstra exatamente a evolução do pensamento humano. A percepção desse corpo ocorre em razão dos aspectos culturais, religiosos, econômicos e políticos. Entretanto, no existencialismo contemporâneo, a reflexão encontra-se pautada no dualismo "liberdade e necessidade”, “autonomia e dependência”, o eu e o mundo (JONAS, 2004). Logo, sua conceituação perpassa a reflexão da percepção humana e comportamental.

A autopercepção humana demonstra que várias questões emergem do corpo humano, despertando sentimentos, sentidos, destinação e curiosidades. Dessas questões, edificam-se novas propostas de cuidado não só do corpo individual, mas do corpo coletivo. Nesse aspecto, torna-se fundamental a ideia do homem como pessoa singular, dentro de uma cultura e em 
determinado momento histórico.

A compreensão do corpo acompanha os desdobramentos da história, através de variáveis de cultura, momentos do tempo. O caráter religioso é bastante marcante, uma vez que estabelece um rol de posturas em razão do uso do corpo. Esse uso do corpo aparece, com frequência, como algo sacralizado. Para os cristãos modernos, por exemplo, o corpo é a expressão da mais alta dignidade.

O culto ao corpo sacralizado pode ser considerado como referência para o desenvolvimento da própria ciência. Neste sentido, emerge a preocupação com a preservação desse corpo, da necessidade de cuidado, tais como a melhoria do desempenho desse corpo, e a coibição de certas práticas, evitando, assim, uma prática eugênica. O corpo, então, é visto como elemento de dominação, não somente social, mas cultural.

Na concepção contemporânea, o corpo refere-se ao que é definido como uma unidade funcional, mesmo que seccionado em partes posicionadas em lugares diferentes fisicamente, que devem ser protegidos para permitir o direito de toda pessoa à sua autonomia (RODOTÀ, 2010).

Logo, o corpo não compreende somente os limites físicos de contorno de uma unidade, mas, sim, um ambiente múltiplo. Essa percepção demonstra que o corpo pode ocupar vários espaços, quer em dimensões virtuais, quer em dimensões reais. Isso somente se torna possível através de amostras de material biológico humano.

A concepção do corpo como um todo ocorre em virtude da singularidade, visto que essa será preservada por ser elemento individualizador da pessoa humana detentora do corpo.

Portanto, essa nova dimensão do corpo necessita do autogoverno, conferindo o poder de decisão à pessoa humana titular desse corpo, como expressão dos espectros plurais dos direitos da personalidade. A unidade funcional deve ser reconstruída para a garantia de sua articulação, em toda a sua amplitude, nesse novo contexto social, politico, e, principalmente genético.

A proteção do corpo contemporâneo pelo Estado deixa de ser natural para se tornar um direito fundamental da pessoa humana, como expressa a Constituição da República, ao elevar a dignidade da pessoa humana ao patamar de princípio fundamental do Estado Democrático de Direito.

Nesta concepção, tem-se a dilatação dos espaços de liberdade para o exercício dos direitos da personalidade, conforme diplomas constitucionais e internacionais de preservação do corpo, que, residualmente, tendem a proibir a utilização do corpo com o fito de lucro, de 
práticas eugênicas de massa, de clonagem reprodutiva.

Entretanto, trata-se de fenômeno histórico e cultural a concepção do corpo como um bem jurídico, próprio da pessoa humana, à qual é conferido seu autogoverno. Portanto, considera-o como um centro de imputação normativa, estando na categoria do ter e não somente do ser, numa aproximação com a noção de bem da personalidade.

A personalidade, por sua vez, é desenvolvida através de uma moralidade racional, conferida pela capacidade de entendimento de cada pessoa humana e de consciência da lei moral. Isso somente se torna possível através de escolhas. Essas compreendem sua autodeterminação, deliberando a respeito da tutela do corpo humano como bem jurídico. Assim, a autonomia reflete também exercício de propriedade.

Autonomia e propriedade sempre estiveram interligadas, tendo em vista a liberdade de autodeterminação, com repercussão em relação a bens e direitos. Portanto, a cada pessoa humana será facultado construir sua própria identidade, por constituir um desdobramento de liberdades de escolha.

Desse modo, o corpo humano como bem jurídico integra a esfera dos direitos da personalidade, por corresponder à proteção da integridade física.

Os direitos da personalidade consistem em direitos fundamentais, visto que foram positivados pelo Estado como instrumentos de garantia. Instituem-se:

[...] como objeto de especial garantia em face do Estado. Os direitos fundamentais 'seriam um núcleo ou círculo mais restrito de direitos humanos especialmente protegidos pela Constituição’. Dentro da categoria direitos fundamentais surge um conjunto de direitos subjetivos que se distinguem ou caracterizam, não só pelo processo de sua formação, já que foram 'identificados e desenvolvidos pela doutrina jurídico-civil do século XIX, tendo à frente Otto von Gierke’, como também pelo objeto de sua tutela, os valores essenciais da personalidade humana. Nessa perspectiva, todos os direitos da personalidade são direitos fundamentais, mas não o inverso. (AMARAL, 2002, p. 255).

Neste sentido, os direitos da personalidade são inerentes à pessoa humana, uma vez que são essenciais para efetivação da personalidade, tratando-se de

[...] direitos subjetivos, assim considerados pela maioria da doutrina, possuindo as seguintes características: são intransmissíveis, absolutos (eficácia erga omnes), indisponíveis (aspecto não absoluto, tendo em vista a possibilidade da renúncia pelo titular até certo limite, como exemplo a disposição de imagem para fins de publicidade, a disposição gratuita de tecidos e órgãos em vida ou após a morte para fins de transplante e tratamento, entre outros), imprescritíveis e extrapatrimoniais [...] (FARIA; SILVA, 2013, p. 174). 
Logo, compete ao Estado Democrático de Direito sua observância e proteção. Portanto, tem-se que "a autonomia privada se insere num contexto de respeito à liberdade e à dignidade da pessoa, não havendo espaço para a instituição de poderes exteriores, como o poder político, o poder médico e o poder de mercado" (RODOTÀ, 2010, p. 315, tradução nossa) 3 .

Neste sentido, o direito ao corpo compreende um dos direitos da personalidade. Assim, compete ao Estado a proteção desse direito, por sua relação estreita com o direito à integridade física. O intuito é consagrar e efetivar dignidade da pessoa humana, princípio constitucionalmente assegurado, fundamento do Estado Democrático de Direito.

\section{A DOAÇÃo NEUTRA COMO ATO DE DISPOSIÇÃo DO CORPO PARA BIOBANCOS DE REPRODUÇÃO HUMANA}

A evolução da concepção do corpo demonstra que esse deixa de ser entendido como uma unidade orgânica, de maneira que passa a poder ocupar diversos espaços, constituindo-se como uma unidade funcional, dotada de imortalidade, pois não compreende somente os limites físicos de contorno de dessa unidade.

Neste cenário, a proteção pelo Estado Democrático de Direito das relações jurídicas de caráter existencial que envolvam os atos de disposição do corpo revela que o ordenamento existente não é mais suficiente para regular e tutelar essas novas perspectivas.

Assim, ao "[...] lado dessa transformação antropológica, novas tecnologias, novas possibilidades de alterações corporais também contribuíram para a mudança do sentido e do conteúdo da autonomia, o que corrobora a necessidade de seu repensar sob o viés existencial” (TEIXEIRA, 2010, p. 136).

Portanto, o corpo deve ser entendido como bem jurídico tutelável, assim como sua proteção, visto que

[...] através daquele bem jurídico são protegidos não apenas o conjunto corporal organizado, mas inclusivamente os múltiplos elementos anatômicos que integram a constituição físico-somática e o equipamento psíquico do homem bem como as relações fisiológicas decorrentes da pertença de cada um desses elementos a estruturas e funções intermédias e ao conjunto do corpo nomeadamente quando se traduzem num estado de saúde físio-psíquica. (CAPELO DE SOUSA, 1995, p. 213-214).

A autonomia surge no contexto jurídico como um princípio dotado de um poder de

\footnotetext{
${ }^{3}$ La autodeterminación se inscribe así em um contexto de respeto a la libertad y a la dignidade de la persona que no deja espacio a la imposición de poderes externos — el poder politico, el poder médico, el poder del mercado.
} 
decisão, de realização de escolha nas relações interpessoais. Por conseguinte, demonstra-se tratar de um sistema de direito autônomo fundamental para a consagração da dignidade humana.

O consentimento por parte do titular do material biológico humano para doação desse material para a instituição de biobancos de reprodução humana é indispensável, uma vez que consiste na expressão de sua vontade.

Logo, o consentimento para os atos de disposição do corpo humano compreende uma “[...] maneira de salvaguardar e proteger a dignidade do ser humano, seja como paciente, seja como sujeito de pesquisa” (BERALDO, 2010, p. 26), que consiste em um dos requisitos da bioética, com intuito de conferir mais humanidade.

Considerando tratar-se de diretos existenciais, o respeito aos direitos da personalidade efetiva a dignidade humana, por meio do exercício de autodeterminação. Torna-se fundamental o direito de informação, de modo claro, inteligível e preciso. O intuito de habilitar a pessoa humana à formação de sua racionalidade moral para consentir na intervenção em sua integridade física há de estar presente e pode ser exigido, como dever de conduta.

Logo, a preocupação com o consentimento para atos de disposição do corpo é relevante, visto que o titular do material biológico humano pode exercer sua autonomia privada ao concordar com o armazenamento e destinação de seu material biológico. Afinal, o uso do corpo na área médica justifica-se na medida em que a intervenção de um profissional, com caráter científico, pode buscar o desenvolvimento da técnica para uma vida saudável (STANCIOLI; CARVALHO, 2011).

Diante disso, a disposição do corpo possui caráter personalíssimo, advindo da autonomia privada, percebida, inclusive, como exercício de propriedade, sendo conferida a cada pessoa humana a aptidão de autodeterminação. Assim, a

[...] relação existente entre a transmissibilidade e a disponibilidade compreende-se com facilidade, desde que uma das causas de mudança do sujeito dos direitos é precisamente a vontade do seu titular, a qual reveste relevância jurídica por virtude da existência da referida faculdade de disposição. (CUPIS, 2004, p. 56).

Logo, a faculdade de disposição consiste na liberalidade conferida ao titular do material biológico humano. A liberalidade compreende um dos elementos pressupostos indeléveis à formação do contrato de doação neutra, fruto de releitura da doação, que se torna possível em se tratando de negócio que concerne à esfera existencial, com significativa expressão de caráter extrapatrimonial.

O ato de disposição do corpo será realizado através de um termo de consentimento. Esse, 
por sua vez, deverá atender aos requisitos de validade do negócio jurídico, previstos no digesto civil, quais sejam, agente capaz, objeto lícito e forma prescrita ou não defesa em lei.

Trata-se de um negócio jurídico existencial cujo reconhecimento deverá demonstrar a constituição do instituto da doação neutra com a previsão das cláusulas de inalienabilidade, impenhorabilidade, incomunicabilidade e a de reversão, com as releituras para seara extrapatrimonial. Além dessas cláusulas, haverá a garantia da revogação imotivada, por traduzir-se na liberalidade do direito de consentir acerca de matéria ligada a direito da personalidade.

Dessa forma, o titular do material biológico humano deve exercer sua autonomia privada, tendo a liberdade de consentir. Logo, todas as cláusulas e sua respectiva elucidação devem constar do instrumento de formalização do negócio jurídico existencial, qual seja, o Termo de Consentimento Livre e Esclarecido (TCLE).

Assim, o Termo de Consentimento Livre e Esclarecido (TCLE) possui natureza contratual. Entretanto, o objeto não é dotado de valor econômico direto, mas, sim, de caráter extrapatrimonial.

Como dito, a linguagem do Termo de Consentimento Livre e Esclarecido (TCLE) deve ser acessível, devendo ser prestados todos os esclarecimentos aos titulares do material biológico humano, tais como a justificativa, os objetivos e os procedimentos que serão utilizados, e, principalmente, a destinação para a reprodução humana assistida.

Vale ressaltar que a licitude da destinação é, igualmente, determinante da validade, seja por acometer o objeto, seja por atentar contra os limites impostos pelos fins econômicos e sociais.

A licitude quanto a destinação do material biológico humano implica a responsabilidade dos mantenedores de biobancos em informar, de forma transparente, tratando-se como um dever anexo, que repercute, como dito, na validade do negócio jurídico existencial. Esse, por sua vez, deve-se pautar em algum racionalismo científico, capaz de impor limites à destinação e à utilização do material biológico humano para as práticas de reprodução humana, pois o

[...] poder de autodeterminação sobre o corpo próprio não é juridicamente ilimitado, perdendo a sua licitude quando atentar contra o bem superior da vida ou contra o próprio corpo e tornando-se mesmo ilícito quando contrariar uma proibição legal, os bons costumes ou princípios da ordem pública. Acresce que tanto o direito à integridade corporal como o direito de autodeterminação corporal, na hierarquia dos interesses legais, cedem em face de interesses sociais preponderantes, particularmente nas áreas da saúde pública, da justiça e da defesa nacional, que impõem certas condutas corporais [...] (CAPELO DE SOUSA, 1995, p. 226-227). 
Portanto, verifica-se a existência de aspectos relevantes que tocam à licitude no direito de propriedade do corpo humano, assim como a vigência de uma racionalidade alocativa de restrições firmadas pela moralidade e pela meta de preservação da saúde pública.

A validade desse negócio jurídico existencial depende desse desenho no cumprimento de deveres de cuidado, informação e proteção, portanto, de modo que o Termo de Consentimento Livre e Esclarecido (TCLE) deve estar apto a formalizar, com regularidade, atos de disposição do corpo pelo titular do material biológico humano para utilização em biobancos de reprodução humana.

\section{AS PRÁTICAS DE REPRODUÇÃO HUMANA ASSISTIDA E OS BIOBANCOS}

Nos dias atuais, o corpo humano é entendido como patrimônio, de cunho prevalentemente existencial. Assim, confere a extrapatrimonialidade por consistir no patrimônio genético, bem como no conjunto de partes separadas do corpo. Logo, deve ser observado o respeito à sua integridade.

Disso decorre a proteção estatal e a normativa voltada à sua preservação, uma vez que “[...] o direito ao corpo diz respeito à proteção destinada à vida humana e à integridade física, englobando o corpo vivo, bem assim como o cadáver (direito ao corpo morto)” (FARIAS; ROSENVALD, 2011, p. 180).

Dessa forma, o direito ao corpo constitui um potencial de exercício de dignidade humana, visto que “[...] a dignidade humana engloba necessariamente respeito e proteção da integridade física e emocional (psíquica) em geral da pessoa [...]” (SARLET, 2006, p. 88).

O patrimônio genético integra, assim, o mínimo patrimonial de cada pessoa humana, por compreender o corpo humano como um bem tutelado pelo Estado. Logo, consta-se a necessidade de releitura do instituto da doação.

A doação define-se como um “[...] contrato em que uma pessoa, por liberalidade, transfere bens de seu patrimônio para o de outra, que os aceita” (FIÚZA, 2014, p. 648).

O instituto privatístico da doação possui uma concepção patrimonializada, ou seja, volta-se ao patrimônio físico, sendo dotado de valor econômico a ser transferido para um terceiro a título gratuito.

Diante da conceituação do instituto da doação, tem-se que ela pode ser aplicada ao patrimônio genético da pessoa humana, especialmente em consideração às percepções mais atuais do corpo humano e dos direitos que gravitam em seu entorno. Logo, a disposição de 
material biológico humano para biobancos destinados à reprodução humana configura espécie de doação.

Nessa acepção, a disposição deve ser entendida como um ato de liberalidade, sem caráter econômico, sendo a amostra biológica destinada a um terceiro para realização de seu projeto pessoal, qual seja, ter uma descendência social, ainda que não biológica. Trata-se de roupagem ajustada de instituto de Direito Privado que emerge da interação entre biotecnologia e ordenamento jurídico, qual seja, a doação neutra que tem como objeto material biológico humano.

A doação neutra é no ato de liberalidade, haja vista que nenhuma pessoa humana pode ser obrigada a dispor de seu material biológico humano para utilização de técnicas de reprodução humana. Além disso, no atual estado de coisas, não pode auferir o recebimento de qualquer vantagem econômica, demonstrando, assim, não ser onerosa a relação formatada como doação, pois

\footnotetext{
O ato de doar material biológico humano para a realização da pesquisa e autorizar o seu armazenamento em URBs ou biobancos de instituições públicas ou privadas sem fins comerciais está imbuído de um sentimento de solidariedade humana e tem como fim o benefício comum. Caberia, assim, tratá-lo com as regras atinentes ao contrato de doação, [...] (MARTINS-COSTA; FERNANDES, 2012, p. 229).
}

A falta de onerosidade e a ausência de beneficio econômico direto da disposição de material biológico humano compreende um dos princípios da Bioética, respeitados pela Biotecnologia.

O Termo de Consentimento Livre e Esclarecido (TCLE) configura instrumento de efetivação da doação neutra, eis que se apresenta como uma espécie de contrato, tendo em vista a manifestação de vontade das partes, vontade que é dos titulares do material biológico humano em doá-lo e dos biobancos em recebê-lo, não havendo, assim, circulação de riquezas, tendo em vista a prevalência do caráter extrapatrimonial.

Assim, o Termo de Consentimento Livre e Esclarecido (TCLE) deve ser visto como instrumento de um negócio jurídico existencial, pois é relacionado com o contrato de doação de material biológico humano.

O material biológico humano pode decorrer de partes fragmentadas do corpo humano. Segundo a Declaração Internacional sobre Dados Genéticos Humanos, a amostra biológica 
humana ${ }^{4}$ consiste em amostra de material biológico dotado de informações genéticas de seu titular. Logo, trata-se de patrimônio genético. Esse, por sua vez, integra o patrimônio mínimo da pessoa humana e ganha especial proteção do Estado. O instituto da doação, concebida como de doação neutra, possui o condão de instrumentalizar os interesses envolvidos no panorama exposto.

\begin{abstract}
A atividade de biobancos envolve diretamente os interesses dos sujeitos da pesquisa, atingindo, também - ainda que por via reflexa —, o interesse público (ou interesse da sociedade em geral). Por essa razão, as políticas adotadas têm sido objeto de particular discussão, notadamente em que seus aspectos sociais, jurídicos e éticos, seja por parte de pesquisadores, seja institucionalmente, por organizações internacionais. (MARTINS-COSTA; FERNANDES, 2012, p. 239).
\end{abstract}

Diante disso, para o reconhecimento da doação neutra é indispensável o consentimento, que deverá observar a boa-fé objetiva, que espraiará efeitos, inclusive, para a formatação do Termo de Consentimento Livre e Esclarecido (TCLE).

Logo, o material biológico humano doado como expressão da doação neutra para biobancos deve observar sua destinação.

A história da humanidade ocidental é marcada por inúmeras recomendações para que o homem e a mulher se reproduzam, tendo como traço latente o caráter religioso, presente na narrativa bíblica, com intuito de perpetuação da sua linhagem familiar. Esse fator cultural pode ser o motivador prevalente em projetos de vida particulares. Independentemente de sua justificação marginal ao direito, cabe ao sistema jurídico e à tecnologia a promoção das conduções para o desenvolvimento da dignidade da pessoa.

Neste contexto, a genética não tardou a apresentar soluções para pessoas, para a realização de seus projetos parentais. As técnicas de reprodução humana assistida representam, assim, um caminho de concretização e exercício de liberdades.

Por reprodução humana medicamente assistida, entende-se um conjunto de procedimentos médicos realizados tanto em homens quanto em mulheres, individualmente ou em entidades familiares livremente formatadas, cujo objetivo é transpor possíveis limitações de ordem social, moral, física. É comum a ideia de que as técnicas de reprodução humana assistida se voltam, primordialmente, a suprir a limitação imposta pela esterilidade. Segundo Nomura (2015, p. 67):

$4 \quad$ Amostra biológica: qualquer amostra de material biológico (por exemplo, células do sangue, da pele e dos ossos ou plasma sanguíneo) em que estejam presentes ácidos nucleicos e que contenha a constituição genética característica de um indivíduo (art. 2º IV). 
Na reprodução humana assistida utiliza-se um conjunto de técnicas que visam unir, artificialmente, os gametas feminino e masculino no aparelho genital feminino, dando origem ao embrião. Essas técnicas vão desde a introdução de gametas masculino no aparelho genital feminino por meios artificiais até a sofisticada fertilização in vitro (FIV).

As técnicas de reprodução humana medicamente assistida podem ser realizadas de forma homóloga ou heteróloga, sendo que, na primeira, é usado, apenas, o material biológico dos futuros pais (sêmen e óvulo). Na forma heteróloga, todavia, é usado material biológico de terceiro, isto é, um doador de material biológico.

Logo, a reprodução humana assistida na forma heteróloga depende de doação neutra, pois utilizará de material biológico humano constante de biobancos.

Os biobancos possuem atividades diferentes, com características específicas, podendo ter várias destinações.

Os biobancos são "uma coleção organizada de material biológico humano e suas informações associadas, armazenados para fins de pesquisa, conforme recomendações e/ou normas técnicas, éticas e operacionais predefinidas” (ASHTON-PROLLA et al., 2009, p. 74).

Logo, o doador do material biológico humano celebra um negócio jurídico existencial através do Termo de Consentimento Livre e Esclarecido (TCLE) com os mantenedores de biobancos de reprodução humana, através do instituto da doação neutra, como forma de viabilização de realização de projeto parental de terceiro.

\section{A ANONIMIZAÇÃO DO DOADOR DO MATERIAL BIOLOGICO HUMANO NOS BIOBANCOS DE REPRODUÇÃO HUMANA}

A pessoa humana traz uma constituição genética única. Diante disso, a identidade de uma pessoa não deve ser limitada, apenas, às suas características biológicas.

Sendo assim, Taylor (1997, p. 44) define identidade da seguinte forma:

Saber quem eu sou é uma espécie de saber em que posição me coloco. Minha identidade é definida pelos compromissos e identificações que proporcionam a estrutura ou o horizonte em cujo âmbito posso tentar determinar caso a caso o que é bom, ou valioso, ou o que se deveria fazer ou aquilo que endosso ou a que me oponho. Em outros termos, trata-se do horizonte dentro do qual sou capaz de tomar uma posição. 
Neste sentido, segundo o autor, a identidade possui duas facetas: uma de cunho histórico e outra de cunho não histórico. A primeira refere-se a autocompreensões e pré-compreensões que o indivíduo adquire ao longo de sua vida. Desta forma, uma pessoa que se afirma católica ou, outra, que se diz anarquista revela, com isso, uma parcela da própria identidade (TAYLOR, 1997, p. 45). A faceta não histórica, por sua vez, diz respeito à autocompreensão do indivíduo diante dos outros, ou seja, saber em que posição se encontra a fim de responder por si mesmo.

A concepção da identidade, também, deve ser realizada sob outro aspecto, qual seja, o corpo. Para Boécio (2005), a definição da pessoa pressupõe a existência de um corpo, diferenciando dos demais seres em virtude da racionalidade. O corpo deve ser entendido como um veículo para expressão de identidade pessoal e social.

Portanto, tem-se a pessoalidade como o resultado, em constante edificação, do livre exercício de liberdade, sendo essa entendida como um espaço para sua construção.

Logo, a identidade também é fruto do exercício da autonomia privada.

O consentimento do doador do material biológico humano para biobancos de reprodução humana consiste em exercício de sua autonomia, com a compreensão da autodeterminação que se concretiza no desejo de transferir material genético aos bancos de material biológico para reprodução humana medicamente assistida, consagrando, assim, seus direitos da personalidade.

Esse consentimento somente se torna possível através da concepção do corpo humano como patrimônio genético desprovido de valor econômico.

Como exercício de sua autodeterminação, compete à pessoa humana as decisões a serem tomadas a respeito da destinação de seu material genético.

Neste sentido, para a realização das técnicas de reprodução humana heteróloga medicamente assistida há a necessidade de material biológico doado. Entretanto, não há que se falar em acesso à identidade pessoal e social do doador do material biológico humano, visto que ao celebrar o negócio jurídico existencial (TCLE), o doador dispõe de seu material, através da doação neutra, desvinculado, assim, de sua pessoalidade.

A anonimização da pessoa e da identidade social constitui garantia da confidencialidade e no gerenciamento dessas informações e no ocultamento da origem socialmente identificada do material biológico humano nesses biobancos, haja vista que essa conduta compreende o sigilo dessas informações, pois as pessoas que doam o material biológico humano têm o “direito 
à confidencialidade, que inclui o direito de preservar o anonimato [confidencialidade] do patrimônio genético, sabendo-se que o conhecimento da estrutura genética de uma pessoa é elemento suscetível ao atingimento da intimidade” (MARTINS-COSTA; FERNANDES, 2012, p. 243).

O intuito de preservar a anonimização, pela via da privacidade e a confidencialidade do titular do material biológico, rumam à proteção jurídica dos direitos da personalidade do doador desse material, por se tratar de pessoa humana:

Os aspectos jurídicos, provavelmente de maior interesse na presente preocupação é a
proteção das informações relacionadas com os indivíduos de origem, tendo em conta
a capacidade potencialmente preditiva ou pré-sintomática da informação que poderia
ser obtida com base em testes genéticos feitos nesses materiais. Há preocupação de
que tal informação pode ter seu uso abusado e o direito de ter controle sobre suas
informações genéticas, pois compreende o direito à privacidade e à vida privada, e a
proibição de discriminação e estigmatização, havendo o receio de não serem
respeitados suficientemente. (ROMEO CASABONA; SIMON, 2011, p. 06, tradução
nossa). ${ }^{5}$

Portanto, a autonomia é pressuposto da pessoa humana para desenvolvimento e construção de sua identidade pessoal e social. Essa, por sua vez, contém em si mesmo um núcleo de variáveis. As variáveis hão de se desenvolver fundadas na moralidade racional individual, que conduz a processos de deliberação de natureza discursiva. Logo, esse é o espaço em que a heteronomia atua para regular o exercício em um plano existencial intersubjetivo.

Vale dizer, para efetivação do livre desenvolvimento da pessoalidade e da personalidade, é imprescindível um Estado plural, visto que o

[...] poder construir a pessoalidade pelo exercício da liberdade com o outro e contra o outro implica assumir a existência de uma sociedade pluralista, que não determina e impõe um projeto de 'vida-boa', mas que reconhece na possibilidade de construção das pessoalidades a existência de variados projetos de 'vidas-boas' [...] (SÁ; MOUREIRA, 2012, p. 28).

\footnotetext{
$5 \quad$ The legal aspects probably of greatest interest at present concern the protection of information relating to the source individuals, particularly in view of the potentially predictive or pre-symptomatic capacity of the information that could be obtained from genetic tests made on these materials. There is concern that such information can be abused and that the right to have control over one's own genetic information, the right to privacy and private life, and the prohibition of discrimination and stigmatisation will not sufficiently respected.
} 
Logo, os direitos da personalidade do doador do material biológico humano de ter sua identidade pessoal e social preservada decorre, em concreto, da falta de consentimento para divulgação dessa informação. Significa que o negócio jurídico existencial que congrega direitos e garantias fundamentais ligados à dignidade da pessoa humana tem seus parâmetros pela pessoa humana, que tem a prerrogativa de definir a finalidade de seu patrimônio genético e biológico, através da doação neutra.

Neste sentido, o Provimento n. 63 do Conselho Nacional de Justiça (2017) dispõe a respeito do registro civil de crianças frutos de reprodução humana assistida, sendo que suas orientações devem ser interpretadas em consonância com os direitos fundamentais horizontalmente eficazes na proteção dos direitos da personalidade. Significa que os direitos da personalidade merecem proteção prevalente, mesmo diante da determinação de exibição da declaração do diretor técnico dos beneficiários com as práticas. O arsenal teórico trazido permite, assim, sustentar que a possibilidade de conhecimento da ancestralidade biológica, que se refere a dados genéticos, não acomete, ou pelo menos não pode acometer, a ocultação da identidade pessoal e social, se esse for o propósito do titular da amostra na doação neutra.

Assim, cabe afirmar que são salvaguardados os direitos da personalidade do doador do material biológico humano, assim, como da criança fruto das práticas heterólogas da fertilização.

Portanto, é também direito da personalidade o acesso às informações genéticas do doador do material biológico humano, com intuito de preservação da integridade física da pessoa humana fruto de reprodução humana medicamente assistida. Esse direito não possui espectro além dos limites reconhecidos à dignidade do doador.

Logo, vale frisar: o acesso a essas informações genéticas irá resguardar a saúde, vista sob a concepção de direito-saúde que possui tutela jurídico-política do Estado Democrático de Direito, por ser definida como direito de autodeterminação da pessoa humana, através do livre desenvolvimento de sua personalidade.

Constata-se que, nessa perspectiva interpretativa multidimensional da identidade, não haverá violação dos direitos da personalidade, quer do doador do material biológico humano, quer da pessoa humana fruto de fertilização heteróloga, uma vez que será resguardada a anonimização (confidencialidade), pela via da privacidade decisional do doador. 
No mesmo provimento do Conselho Nacional de Justiça, fala-se em conhecimento da ascendência biológica. Portanto, não há que se confundir ascendência biológica com a identidade pessoal e social, isto é, a pessoalidade do doador do material biológico humano.

Portanto, a leitura a ser realizada acerca do conhecimento da ancestralidade biológica compreende somente os dados genéticos e biológicos, para resguardar a confidencialidade no que toca aos demais direitos da personalidade do doador, não sendo, admissível, em nenhuma hipótese, a divulgação de sua identidade pessoal e social, por constituírem acepções distintas. Significa que, em uma perspectiva multidimensional da identidade, apenas dados ligados ao interesse meramente genético e biológico desprendem-se da identidade do doador do material.

\section{CONCLUSÃO}

Se a Biotecnologia impõe desafios ao Direito em razão do desenvolvimento de novas possibilidades para a realização dos projetos de vida particulares e sociais, é certo que cabe ao Direito buscar soluções para as celeumas derivadas dessa interação.

A pessoa que dispõe de material biológico humano pode, ao teor do Provimento n. 63 do Conselho Nacional de Justiça (2017), sofrer violações de seus direitos da personalidade, seja pela inobservância de seu desejo de anonimização para a não revelação de aspectos de sua pessoalidade, seja pelo desrespeito à sua forma de construção de dignidade.

Assim, o direito ao conhecimento da ascendência biológica e a obrigatoriedade, no registro civil, da apresentação da declaração firmada pelo responsável diretor técnico indicando a realização das práticas de reprodução humana assistida (na qual constaram os beneficiários) não significam, necessariamente, a exposição de dados que excedem a dimensão biológica.

Logo, através da leitura do $\S 3^{\circ}$ do art. 17 do referimento provimento, percebe-se que o conflito entre o direito a um eventual conhecimento da ascendência biológica da criança gerada a partir da utilização de técnicas de reprodução humana heteróloga e o direito à anonimização do doador, entendida como a confidencialidade de seus dados identitários, é apenas aparente. Apesar de a documentação dever ser apresentada ao serviço registral, não deve haver menção à identidade pessoal e social. Explica-se.

A possibilidade que se reconhece é de acesso às informações genéticas ligadas ao doador do material biológico humano, sem revelação de identidade pessoal e social. Afinal, o negócio jurídico existencial da doação neutra de material biológico humano pressupõe a 
conformação de pessoalidades. Aqui, cabe, portanto, a dissociação entre dados do material biológico, vale dizer, informações dessa ancestralidade, e a identidade multidimensional, que compreende aspectos social e pessoal do doador. Afinal, a autonomia privada que reflete a dignidade construída pelo doador é compatível com o instituto da doação neutra, que consegue preservar espaço aos seus direitos da personalidade.

Neste sentido, o Provimento n. 63 do Conselho Nacional de Justiça (2017) confirma o desenho de uma identidade multidimensional, de maneira que apenas se desprende da esfera de prerrogativas do doador identificadores genéticos e biológicos. Significa que a provisão em comento não afasta a preservação dos direitos da personalidade de todos os envolvidos, de modo que não impõe a desocultação de identidade pessoal e social do doador.

\section{REFERENCIAS}

AMARAL, Francisco. Direito civil: introdução. 7. ed. Rio de Janeiro: Renovar, 2002.

ARRIBAS, Maria Concepción Martín; DÍAZ, Javier Arias. Biobancos y utilización de muestras de origem humano em investigación quirúrgica. Marco Normativo Actual. Revista Cirurgia Española - CIR ESP, Madrid, v. 89, n. 4, p. 207-212, 2011.

ASHTON-PROLLA, Patrícia et al. Biobanco do Hospital de Clínicas de Porto Alegre: aspectos técnicos, éticos, jurídicos e sociais. Revista HCPA, Porto Alegre, v. 29, n.1, p. 74-79, 2009.

BERALDO, Ana de Moraes. Bioética, biodireito e consentimento informado. Revista Trimestral de Direito Civil, Rio de Janeiro, v. 11, n. 41, p. 21-43, jan./mar. 2010.

BOÉCIO. Escritos. São Paulo: Martins Fontes, 2005.

BRASIL. Constituição (1988). Constituição da República Federativa do Brasil, de 05 de outubro de 1988. Diário Oficial da União, Brasília, 05 out. 1988. Disponível em: <http://ww w.planalto.gov.br/ccivil_03/Constituicao/Constituicao.htm>. Acesso em: 10 mar. 2018.

BRASIL. Lei n ${ }^{\circ}$ 10.406, de 10 janeiro de 2002. Institui o Código Civil. Diário Oficial da União, Brasília, 11 jan. 2002. Disponível em: <http://www.planalto.gov.br/ccivil_03/Leis/ 2002/L10406.htm>. Acesso em: 10 mar. 2018.

BRASIL. Ministério da Saúde. Portaria n 2.201, de 14 de setembro de 2011. Estabelece as Diretrizes Nacionais para Biorrepositório e Biobanco de Material Biológico Humano com Finalidade de Pesquisa. Diário Oficial da União, Brasília, 15 set. 2011. Disponível em: <http://bvs ms.saude.gov.br/bvs/saudelegis/2011/prt2201_14_09_2011.html>. Acesso em: 05 mar. 2018. 
BRASIL. Conselho Nacional de Justiça. Provimento n ${ }^{\circ}$ 63, de 14 de novembro de 2017. Institui modelos únicos de certidão de nascimento, de casamento e de óbito, a serem adotadas pelos ofícios de registro civil das pessoas naturais, e dispõe sobre o reconhecimento voluntário e a averbação da paternidade e maternidade socioafetiva no Livro "A” e sobre o registro de nascimento e emissão da respectiva certidão dos filhos havidos por reprodução assistida. Diário Oficial da União, Brasília, 17 nov.2017. Disponível em:

<http://www.cnj.jus.br///images/atos_normativos/provimento/provimento_63_14112017_190 32018150944.pdf>. Acesso em: 08 mar. 2018.

CAPELO DE SOUSA, Rabindranath Valentino Aleixo. O direito geral de personalidade. Coimbra: Coimbra Editora, 1995.

CONSELHO NACIONAL DE SAÚDE. Resolução CNS nº 441, de 12 de maio de 2011. Aprovar as seguintes diretrizes para análise ética de projetos de pesquisas que envolvam armazenamento de material biológico humano ou uso de material armazenado em pesquisas anteriores. Diário Oficial União, Brasília, 18 jul. 2011. Disponível em:

<http://bvsms.saude.gov.br/bvs/saudelegis/cns/2011/res0441_12_05_2011.html>. Acesso em: 20 mar. 2018.

CORDEIRO, Antônio Manuel da Rocha e Menezes. Da boa-fé no direito civil. Coimbra: Almedina, 2007.

CUPIS, Adriano de. Os direitos da personalidade. Campinas, SP: Romana Jurídica, 2004.

FARIA, Alexandra Clara Ferreira; SILVA, Flávia Helena Millard Rosa da. Doação de material genético: um estudo sobre sua permissibilidade jurídica. In: MOUREIRA, Diogo Luna; ALMEIDA, Renata Barbosa de; SÁ, Maria de Fátima Freire de (Coord.). Direito privado: revisitações. Belo Horizonte: Arraes Editores, 2013. p. 171-190.

FARIAS, Cristiano Chaves de; ROSENVALD, Nelson. Direito civil: teoria geral. 9. ed. Rio de Janeiro: Lúmen Júris, 2011.

FIÚZA, César. Direito civil: curso completo. 17. ed. Belo Horizonte: Del Rey, 2014.

MARTINS-COSTA, Judith; FERNANDES, Márcia Santana. Os biobancos e a doação de material biológico humano: um ensaio de qualificação jurídica. In: GOZZO, Débora; LIGIERA, Wilson Ricardo (Org.). Bioética e direitos fundamentais. São Paulo: Saraiva, 2012, p. 223-259.

MOUREIRA, Diogo Luna. Pessoas: a co-relação entre as coordenadas da pessoalidade e as coordenadas da personalidade jurídicas. Dissertação apresentada no Programa de PósGraduação Stricto Sensu em Direito da Pontificia Universidade Católica de Minas Gerais. Disponível em: <http://www.biblioteca.pucminas.br/teses/Direito_MoureiraDL_1.pdf>. Acesso em: 20 ago. 2016. 
NOMURA, Roseli Mieko Yamamoto. Reprodução Humana: Reprodução Assistida, Fertilização in vitro, Inseminação Artificial, Direitos Reprodutivos. In: GIMENES, Antônio Canteiro; BATISTA, Juliana dos Santos; FUJITA, Jorge Shiguemitsu; ROCHA, Renata da (org). Dilemas Acerca da Vida Humana: Interfaces entre a Bioética e o Biodireito. São Paulo: Atheneu, 2015.

RODOTÀ, Stefano. La vida y las reglas: entre el derecho y el no derecho. Madrid: Editorial Trotta, 2010.

ROMEO CASABONA, Carlos María; SIMON, Jurgen W. Biobanking: a chance for scientific research and a challenge for intelectual property rights and privacy. In: ROMEO

CASABONA, Carlos Maria et al. Latinbanks: study on the legal and social implications of creating banks of biological material for biomedical research. Espanha: Bruylant Bruxelles, 2011, p. 05-15.

SÁ, Maria de Fátima Freire de; MOUREIRA, Diogo Luna. Autonomia para morrer: eutanásia, suicídio assistido e diretivas antecipadas de vontade. Belo Horizonte: Del Rey, 2012.

STANCIOLI, Brunello; CARVALHO, Nara Pereira. Da integridade física ao livre uso do corpo: releitura de um direito de personalidade. In: TEIXEIRA, Ana Carolina Brochado; RIBEIRO, Gustavo Pereira Leite (Coord.). Manual de teoria geral do direito civil. Belo Horizonte: Del Rey, 2011, p. 267-285.

TAYLOR, Charles. As fontes do self: a construção da identidade moderna. São Paulo: Loyola, 1997.

TEIXEIRA, Ana Carolina Brochado. Saúde, corpo e autonomia privada. Rio de Janeiro: Renovar, 2010. 